\title{
Impact of Permeation Properties and Backsheet-Encapsulant Interactions on the Reliability of PV Modules
}

\author{
Cornelia Peike, Philip Hülsmann, Matthias Blüml, Philipp Schmid, \\ Karl-Anders Weiß, and Michael Köhl \\ Fraunhofer-Institut für Solare Energiesysteme ISE, 79110 Freiburg, Germany \\ Correspondence should be addressed to Cornelia Peike, cornelia.peike@ise.fraunhofer.de
}

Received 27 April 2012; Accepted 9 July 2012

Academic Editors: F. E. Little, Y. Matsumoto, and S. Senthilarasu

Copyright (c) 2012 Cornelia Peike et al. This is an open access article distributed under the Creative Commons Attribution License, which permits unrestricted use, distribution, and reproduction in any medium, provided the original work is properly cited.

\begin{abstract}
The reliability of photovoltaic modules is highly influenced by the material properties of the backsheet and encapsulation material. Currently, little attention is paid to the permeation properties of the back-sheet material or to its impact on encapsulation degradation and module reliability. We investigated the interaction of different types of solar encapsulation and back-sheet materials. Therefore, various laminates were made to examine the environmental impact on such materials during the aging processes. One focus of our studylies in oxygen and water vapor permeability of the back-sheet materials. The encapsulants used were an ethylene vinyl acetate (EVA), a TPSE (thermoplastic silicone elastomer), an ionomer, and a PVB (polyvinyl butyral). Backsheet materials were a TPT (Tedlar-PET-Tedlar) foil, a polyamide (PA) sheet and a polyethylene terephthalate (PET) composite film. Raman spectroscopic and FT-IR/vis-reflectance measurements were carried out before and after different accelerated aging procedures. The water vapor and oxygen permeation properties were measured. A clear correlation between the permeation properties and the observed aging behavior was found. The degradation, especially of the encapsulant, resulted in increased fluorescence background in the Raman spectra. It could be shown that the encapsulation-cell-backsheet system should be optimized in order to minimize the stress on the PV-module components.
\end{abstract}

\section{Introduction}

The performance and reliability of a PV module are highly affected by the degradation behavior of the polymeric components within the module, which are mainly the encapsulant and back-sheet material. This degradation of the polymeric components is, in turn, dependent on the weathering conditions caused mainly by UV irradiation, temperature, and humidity. Especially high irradiation doses [1-3], large temperature gradients between night and day [4], and high humidity at high temperature may easily impair the components used. These conditions may induce various kinds of degradation processes in a PV module. One of the most important is the degradation of the encapsulation which causes discoloration [1], leading to transmission losses and delamination. Another major aspect of module degradation is the corrosion of the metallization which is strongly sped up by corrosive products from the encapsulation, for example, acetic acid from EVA. The metallization corrosion leads to an increased series resistance and therefore losses in module performance [5]. Delamination and discoloration of the back-sheet impair the mechanical and aesthetic function and facilitate moisture ingress. Degradation of the anti-reflex coating of the solar cells has been observed in some rare cases. Last but not least, crack formation within the cells causes inactive regions and performance losses. These degrading mechanisms can be prevented most effectively by an intact encapsulation with a suitable elastic modulus.

Various groups have investigated the degradation mechanisms of the most widely used solar encapsulation material, EVA, for the last 20 years [6-8]. Yet for the complexity of the system and permanent advancement of the additive formulations, a complete understanding of the degradation mechanisms of EVA in a PV module has not been gained. The main reasons for discoloration, the primary form of visible degradation, are deacetylation, hydrolysis [9], photothermal 

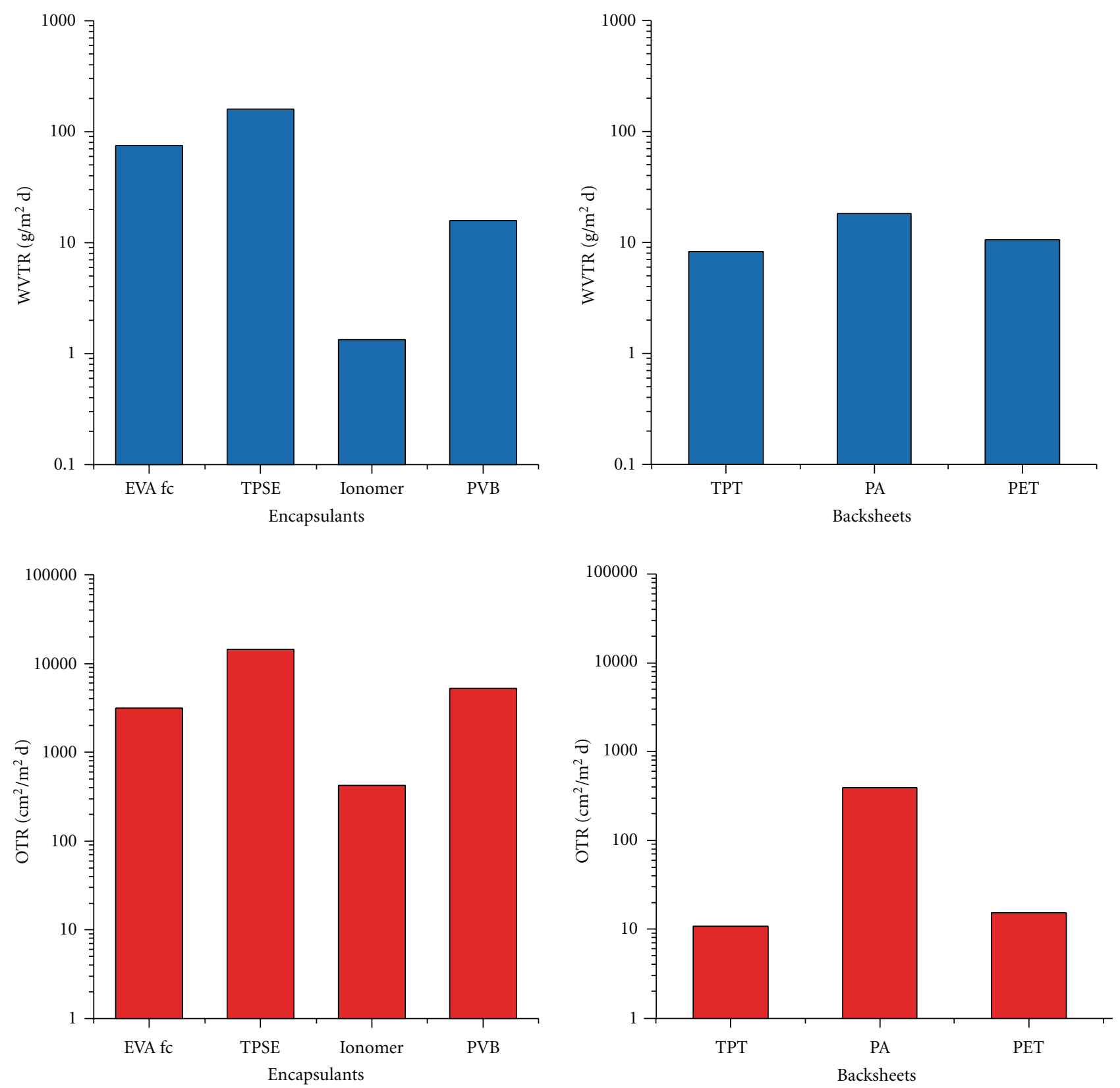

Figure 1: WVTR and OTR of the encapsulants and backsheets used, measured at $85^{\circ} \mathrm{C}$.

decomposition [6, 10, 11], and degradation of additives such as UV light stabilizers, UV absorbers, and antioxidants $[8,12-14]$.

Since these degradation problems have not been solved completely up to now, many new materials have recently been introduced to the PV market which aim for an enhanced reliability and/or lowered manufacturing costs. These materials may represent viable alternatives to the components commonly used, but the interaction between them has not been investigated yet. Our hypothesis is that for some encapsulation/backsheet combinations, the susceptibility to degradation is much lower than that for other combinations.

Especially the permeation properties of the materials are of great importance. As stated, permeates, like water vapor and oxygen, are reaction partners in degradation processes inside PV modules. The ingress of such gases is governed by the permeation properties of the polymeric back-sheets or encapsulation materials used [3]. The permeation properties are also influenced by the ambient climate because of the strong temperature dependence of diffusion processes. These mass transfer processes can be described by Fick's law.

The diffusion coefficient of a material depends on its molecular characteristics. For polymers, these characteristics are chain length, crystallinity, density, chain orientation, and crosslinking. Even the sorption of water or $\mathrm{CO}_{2}$ can [also] lead to a changing permeability for other gases.

It was possible to measure the water vapor transmission rate (WVTR) and oxygen transmission rate (OTR) of 
the materials investigated in a temperature range up to $85^{\circ} \mathrm{C}$, which was the temperature level of the aging tests. It was found that WVTR and OTR were on average higher for the encapsulants than for the back-sheets, and the OTR of PA was two orders of magnitude higher than those of the other back-sheets.

\section{Experimental Procedures}

Laminates were made from low iron solar glass with four different types of encapsulation material (EVA, a TPSE, an ionomer, and a PVB) and three back sheet materials (a TPT foil, a polyamide sheet, and a PET composite film) in a Meier vacuum laminator. Temperatures were varied between $140^{\circ} \mathrm{C}$ (PVB and Ionomer) and $160^{\circ} \mathrm{C}$ (TPSE) for 10 to 14 minutes. A piece of solar cell was incorporated in the encapsulant in order to enable materials interaction investigations. Samples of each laminate type were aged in three different procedures:

(i) under damp heat conditions $\left(85^{\circ} \mathrm{C} / 85 \%\right.$ r.h.) $(\mathrm{DH})$ for up to $1000 \mathrm{~h}$,

(ii) under combined UV/damp heat conditions $\left(85^{\circ} \mathrm{C} /\right.$ $90 \%$ r.h., total dose of $190 \mathrm{kWh} / \mathrm{m}^{2}$, UV-B portion ca. $\left.2 \mathrm{kWh} / \mathrm{m}^{2}\right)(\mathrm{UV} / \mathrm{DH})$ for up to $1000 \mathrm{~h}$,

(iii) with UV light for up to $400 \mathrm{~h}$ with a total irradiation dose of $60 \mathrm{kWh} / \mathrm{m}^{2}$ (UV-B portion $10 \mathrm{kWh} / \mathrm{m}^{2}$ ).

Samples of the back-sheet and encapsulation materials were aged under the same conditions, and their individual aging behavior was investigated by the means of ATR-IR spectroscopy and FT-IR/vis reflectance or transmission measurements.

Permeation was measured according to the method developed by Hülsmann et al. [15]. Samples were placed in the sample holder in a climate cabinet under controlled temperature and humidity. The change in permeates over time was assessed in a mass spectrometer.

The WVTR and OTR of the encapsulation materials and the 3-layered back-sheets (Figure 3 ) were measured at $85^{\circ} \mathrm{C}$. For comparative purposes, the encapsulants were laminated analogous to standard module lamination conditions in between two polytetrafluoroethylene sheets, in order to mount them for permeation measurements. Afterwards, the values for the encapsulants were scaled to a thickness of $1 \mathrm{~mm}$, whereas the results of the back-sheets were unmodified.

\section{Results}

3.1. Permeation Properties. On average the WVTR and OTR for the encapsulants was higher than those for the backsheets (Figure 1). Of the encapsulants, the values of the permeability for TPSE were highest, while the permeability of the ionomer was about two orders of magnitude lower than TPSE.

The WVTR of all back-sheets was very similar. In contrast, the OTR of the PA sheet is almost two orders of magnitude higher than that of the PET-based ones.

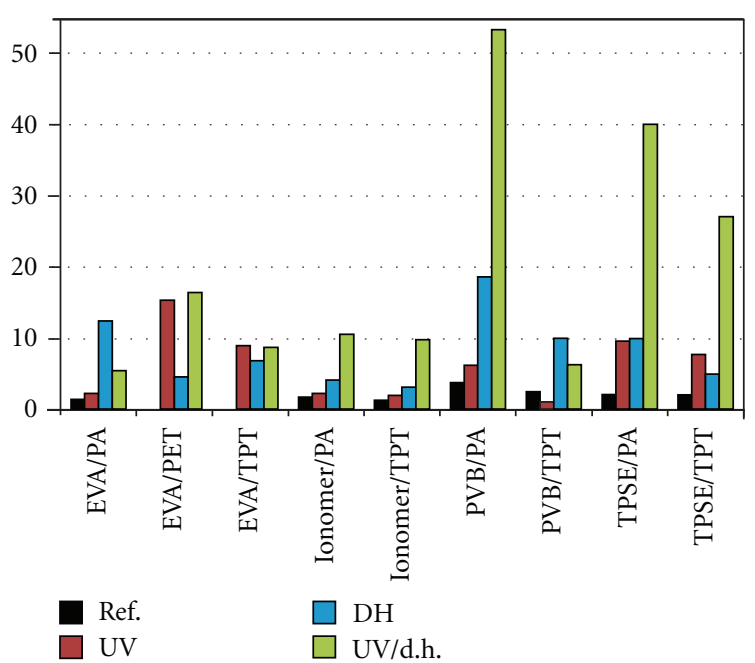

Figure 2: Yellowness indices of the laminates before and after the aging tests.

3.2. Backsheet/Encapsulant Interactions. The spectral reflectance of all laminates decreased after the different aging tests, especially in the visible region. Only hydroxyl vibrations, that is, nonpolymer bands, exhibited a different behavior. After the UV test, reflectance over the range of the hydroxyl vibration increased due to a decreased water absorption.

Yellowness indices were derived from the spectral reflectance measurements (Figure 2). After the combined $\mathrm{UV} / \mathrm{DH}$ test, yellowing was strongest by far in the TPSE/TPT, the TPSE/PA, and the PVB/PA laminates, which was about three to five times higher than the average yellowness index of the other laminates after the UV/DH test. Discoloration resistivity was best for the EVA/PA and the PVB/TPT laminates. Least discoloration after pure $\mathrm{DH}$ and UV aging could be found in the ionomer laminates.

The Raman spectra of the unaged EVA laminates (Figure 3 , marked as reference) showed the typical EVA peaks at 629 $(\nu(\mathrm{CO})), 1067(\nu(\mathrm{CC})), 1126(\nu(\mathrm{CC})), 1295(t(\mathrm{CH}), \delta(\mathrm{CH}))$, $1438(\delta(\mathrm{CH})), 1724(\nu(\mathrm{CO}))$, and 2832, 2863, 2880, 2895, and $2913 \mathrm{~cm}^{-1}\left(\nu\left(\mathrm{CH}_{2}\right)\right.$ and $\left.\nu\left(\mathrm{CH}_{3}\right)\right)$.

When measured beside the cell, the UV and the UV/DH aged EVA/PET and EVA/TPT laminates (EVA/TPT not shown) exhibited an increase in the baseline together with a decrease in relative peak intensities due to a fluorescence background. In contrast, the EVA laminates with a PA backsheet showed only a slight increase in fluorescence after aging procedures with UV irradiation and no alteration in the spectrum after damp heat aging. The fluorescence intensity can be an indicator for polymer degradation since it is correlated to the amount of chromophores formed during degradation. When measured above the cell, all EVA laminates gave similar results with an intense fluorescence background after combined UV/DH-aging and UV-aging but no sign of polymer degradation after $\mathrm{DH}$ aging. This indicates that the differences between the EVA laminates with different back-sheets are most likely caused by the back-sheet's permeation properties. 

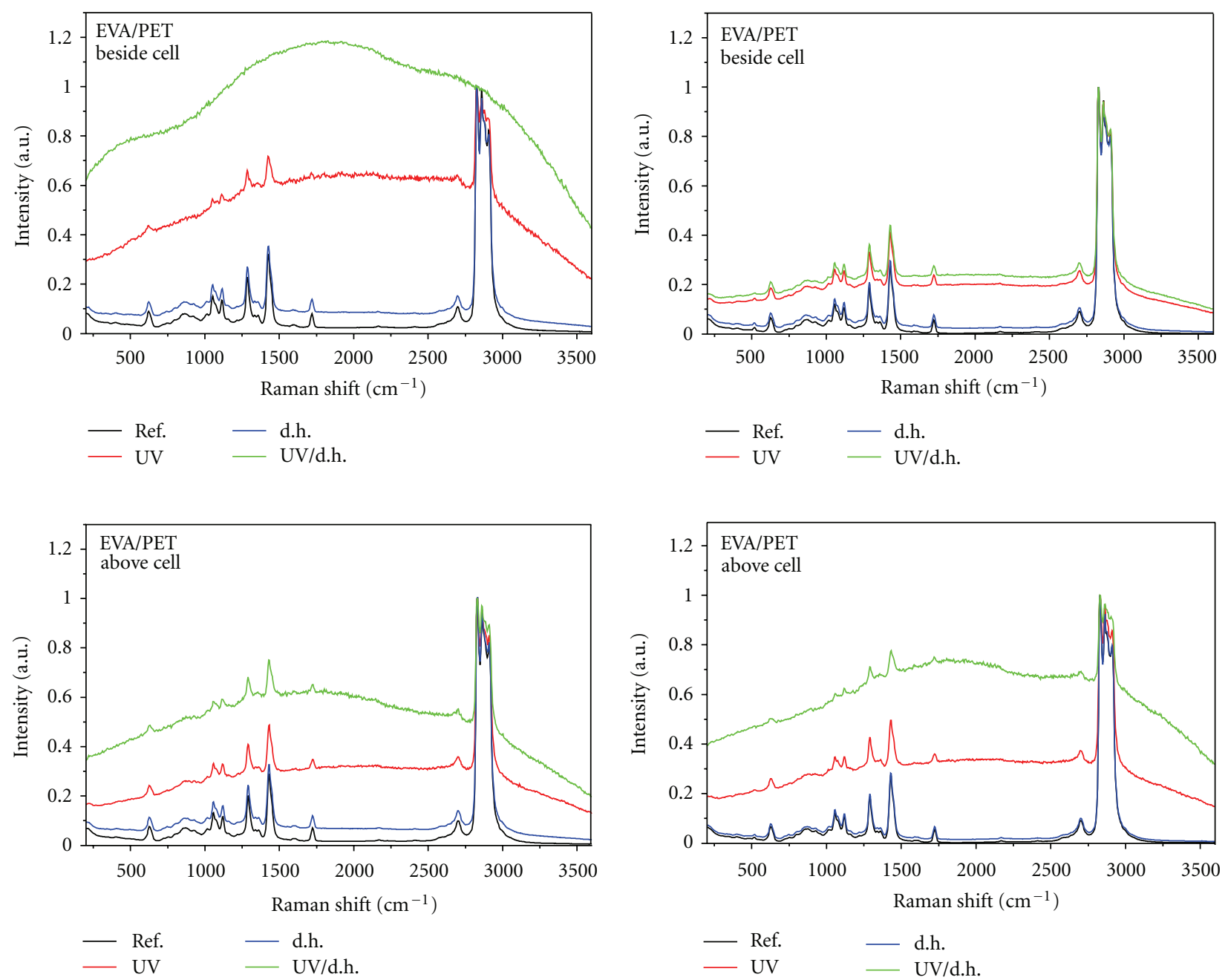

FIGURE 3: Raman spectra of the laminates with encapsulation after different aging conditions.

The ratio of fluorescence intensity to $\mathrm{CH}$ stretching vibrations revealed a strong influence of the back-sheet material on the amount of degradation of the encapsulant (Figure 4). Especially the EVA/PA and PVB/TPT laminates are only slightly degraded after the various aging tests. EVA and TPSE appear to be very sensitive to UV irradiation. Their tendency towards yellowing and fluorescence is considerably improved when combined with a back-sheet which provides high oxygen permeability, thereby enabling bleaching reactions.

\section{Discussion}

WVTR and OTR were on average higher for the encapsulants than for the back-sheets. Therefore, the backsheets can be regarded as a resistor delaying atmospheric gas ingress into the PV module. This result is in accordance with the findings of Kempe et al. [16] on simulated values for moisture ingress into PV modules through breathable and nonbreathable backsheets.

It was found that the polyamide-based back-sheet had an OTR two orders of magnitude higher than the PET-based ones. Therefore, reactions requiring oxygen proceed much more effectively in a module with a PA back-sheet. Hence, encapsulants tending to discoloration due to UV irradiation should be combined with a PA back-sheet.

In contrast, encapsulation materials, which tend to be sensitive to hydrolysis, for example, PVB, need to be combined with a low WVTR back-sheet. The reason for this is the affinity of PVB to a higher water uptake together with a very strong sensitivity to hydrolysis.

A much lower susceptibility to degradation of some encapsulation/back-sheet combinations compared to other combinations could be found. The PVB/TPT and EVA/PA laminates showed least fluorescence after the various aging tests and can therefore be regarded as a very good choice in order to meet the needs for low corrosivity in a PV module.

The chemical nature of the chromophores inducing the po-zlymer aging related fluorescence is subject of current research in our group.

\section{Acknowledgments}

The work was partly funded by the German Federal Ministry for the Environment, Nature Conservation and Nuclear 


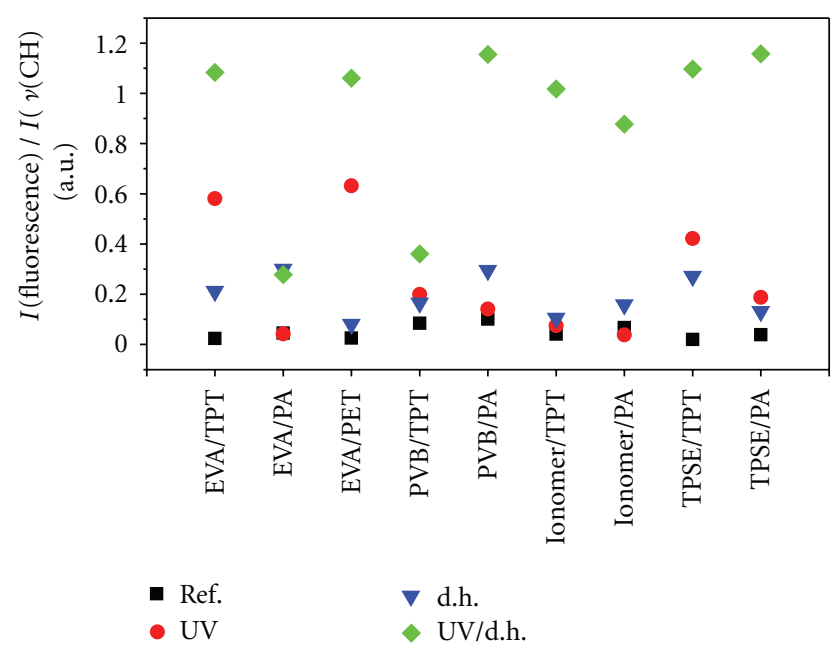

FIGURE 4: Intensity ratio of fluorescence intensity and $\mathrm{CH}$ stretching vibrations of the different laminates before and after UV, damp heat and UV/damp heat aging.

Safety (BMU FKz 0329978) and sponsored by the industrial partners Scheuten Solar, Schott Solar, Solar-Fabrik, Solarwatt, SolarWorld, and Solon.

\section{References}

[1] F. J. Pern, S. H. Glick, and A. W. Czanderna, "EVA encapsulants for PV modules: reliability issues and current R and D status at NREL," Withlacoochee River Electric Cooperative, vol. 8, no. 1-4, pp. 367-370, 1996.

[2] F. J. Pern, "Ethylene-Vinyl Acetate (EVA) encapsulants for photovoltaic modules: degradation and discoloration mechanisms and formulation modifications for improved piiotostability," Angewandte Makromolekulare Chemie, vol. 252, pp. 195-216, 1997.

[3] M. D. Kempe, "Ultraviolet light test and evaluation methods for encapsulants of photovoltaic modules," Solar Energy Materials and Solar Cells, vol. 94, no. 2, pp. 246-253, 2010.

[4] W. Herrmann, N. Bogdanski, F. Reil et al., "PV module degradation caused by thermomechanical stress: real impacts of outdoor weathering versus accelerated testing in the laboratory," in Proceedings of The Special Patrol Insertion/Extraction Optics and Photonics (SPIE '10), San Diego, Calif, USA, 2010.

[5] E. E. van Dyk, J. B. Chamel, and A. R. Gxasheka, "Investigation of delamination in an edge-defined film-fed growth photovoltaic module," Solar Energy Materials and Solar Cells, vol. 88, no. 4, pp. 403-411, 2005.

[6] F. J. Pern and A. W. Czanderna, "EVA degradation mechanisms simulating those in PV modules," in Proceedings of the 11th Photovoltaic Advanced Research and Development Project, Review Meeting, Denver, Colo, USA, 1992.

[7] A. W. Czanderna and F. J. Pern, "Encapsulation of PV modules using ethylene vinyl acetate copolymer as a pottant: a critical review," Solar Energy Materials and Solar Cells, vol. 43, no. 2, pp. 101-181, 1996.

[8] N. S. Allen and M. Edge, Fundamentals of Polymer Degradation and Stabilisation, Elsevier Science Publishers, Essex, UK, 1994.

[9] R. Liang et al., "Photothermal characterization of encapsulant materials for photovoltaic modules," JPL Publication 82-42,
JPL 5101-210, DOE/JPL-1012-72, Jet Propulsion Laboratory, 1982.

[10] M. L. Marín, A. Jiménez, J. López, and J. Vilaplana, “Thermal degradation of ethylene (vinyl acetate). Kinetic analysis of thermogravimetric data," Journal of Thermal Analysis, vol. 47, no. 1, pp. 247-258, 1996.

[11] N. S. Allen, M. Edge, M. Rodriguez, C. M. Liauw, and E. Fontan, "Aspects of the thermal oxidation, yellowing and stabilization of ethylene vinyl acetate copolymer," Polymer Degradation and Stability, vol. 71, no. 1, pp. 1-14, 2000.

[12] P. Klemchuk, M. Ezrin, G. Lavigne, W. H. Holley, J. Galica, and S. Agro, "Investigation of the degradation and stabilization of EVA-based encapsulant in field-aged solar energy modules," Polymer Degradation and Stability, vol. 55, no. 3, pp. 347-365, 1997.

[13] W. H. Holley, S. C. Agro, J. P. Galica et al., "Investigation into the causes of browning in Eva encapsulated flat plate PV modules," in Proceedings of the 24th IEEE Photovoltaic Specialists Conference, pp. 893-896, First WCPEC, Holualoa, Hawaii, USA, December 1994.

[14] M. Rodríguez-Vázquez, C. M. Liauw, N. S. Allen, M. Edge, and E. Fontan, "Degradation and stabilisation of poly(ethylenestat-vinyl acetate): 1-Spectroscopic and rheological examination of thermal and thermo-oxidative degradation mechanisms," Polymer Degradation and Stability, vol. 91, no. 1, pp. 154-164, 2006.

[15] P. Hülsmann, D. Philipp, and M. Köhl, "Measuring temperature-dependent water vapor and gas permeation through high barrier films," Review of Scientific Instruments, vol. 80, no. 11, Article ID 113901, 2009.

[16] M. D. Kempe, S. Kurtz, J. Wohlgemuth, D. Miller, M. O. Reese, and A. A. Dameron, "Modeling of damp heat testing relative to outdoor exposure," in Proceedings of the 21st International Photovoltaic Science and Engineering Conference, Tokyo, Japan, 2011. 

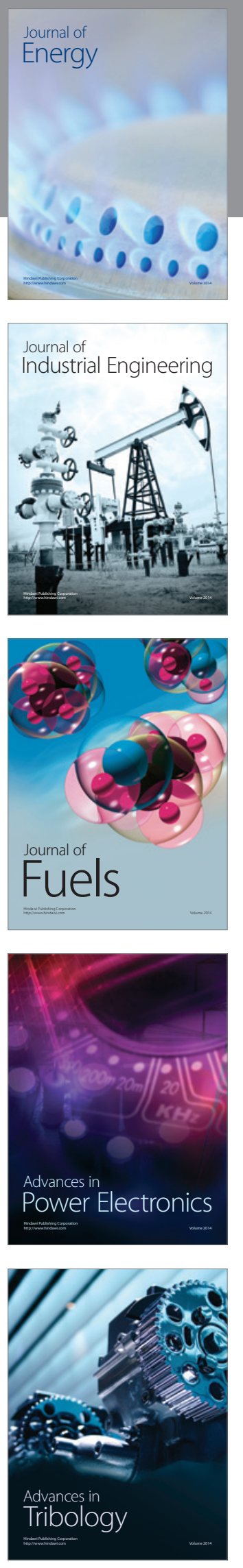
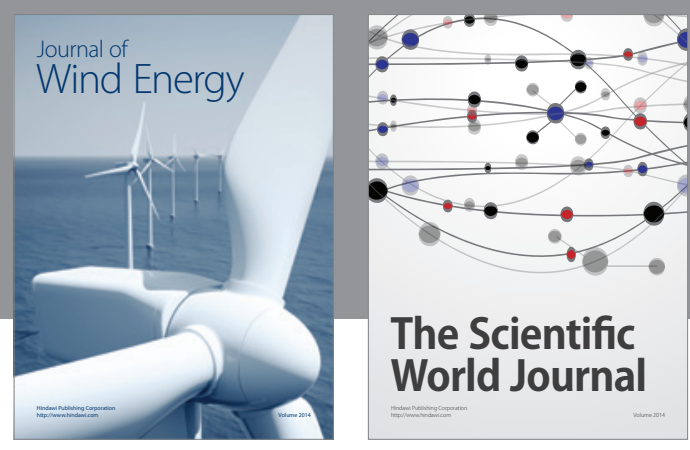

The Scientific World Journal

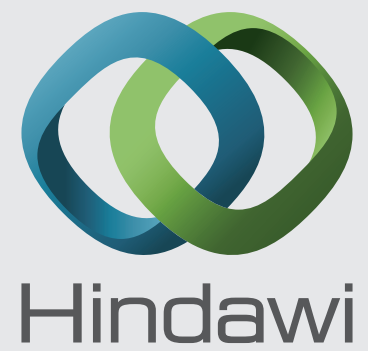

Submit your manuscripts at http://www.hindawi.com
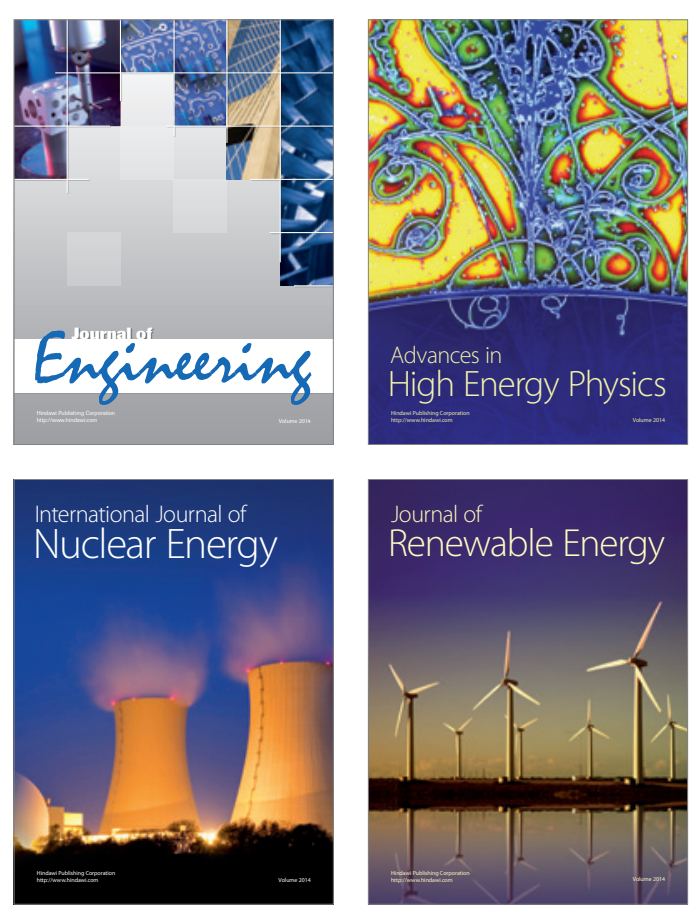

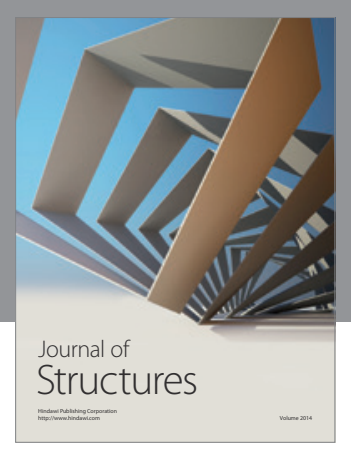

Rotating
Mechinery
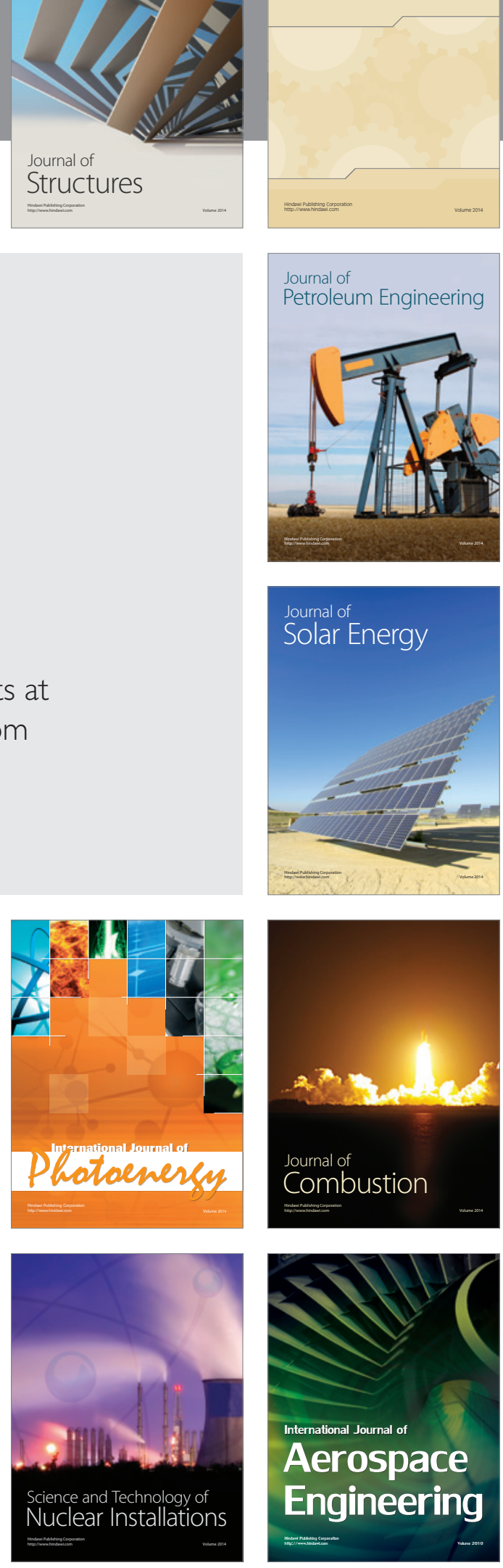